\title{
A ASSOCIAÇÃO ZIRCÃO-BIOTITA COMO UM CRITÉRIO PETROGRÁFICO DE CARACTERIZAÇÃO PRÉ-METAMÓRFICA
}

\author{
JOÃO FERNANDO MARTINS HIPPERTT*
}

\begin{abstract}
The zircon-biotite association is a characteristic textural feature generally observed in igneous and metamorphic rocks. A careful quantification study employing the ratio diagram utilizing the modal biotite $v s$. $100 \times$ Zircon (B)/Zircon (T) could be of great value for getting an exact idea of the sedimentary or igneous origin in metamorphic rocks. For this purpose, a detailed analysis of 82 samples from different localities was carried out with a original petrographic method, and the plotting has demostrated an ideal picture: the plutonics and metaplutonics occupy a distinct area quite different from those of metasediments. The results obtained and corroborative petrographic observations suggest that rounded zircons of metasediments may not be totally representing the residual clastics. The textural aspects indicate that, in may cases, zircon formation is of later origin than the metamorphic biotite nucleation.
\end{abstract}

\begin{abstract}
INTRODUÇÃO $O$ uso do zircão em petrogênese $\mathrm{O}$ zircão é um acessório presente na maioria das rochas ígneas, metamórficas e sedimentares. Pela freqüência com que ocorre, e pelas particularidades de seu modo de ocorrência, tem sido extensivamente utilizado em correlações e interpretações petrogenéticas. Esses trabalhos enfocam a tipologia dos grãos com base em uma ou mais das seguintes características morfológicas: dimensões dos cristais; grau de arredondamento dos grãos; desenvolvimento relativo das diferentes formas cristalograficas.
\end{abstract}

A aplicação das características dimensionaị dos grãos (eixo menor $x$, eixo maior $y$ e elongação $y / x$ ) em interpreta" ções petrogenéticas difundiu-se a partir dos trabalhos de Smithson (1939), Poldervaart $(1950,1955,1956)$, Poldervaart \& Von Backstrom (1950) e Larsen \& Poldervaart (1957). É estatisticamente verdadeiro que zircões igneos têm maiores valores de elongação que zircões clásticos, desgastados por transporte. Este parâmetro, portanto, teria a capacidade de distinguir orto e parametamorfitos, e mesmo granitóides de cristalização primária daqueles anatéticos.

O mesmo se pode dizer do grau de arredondamento. Groves (1930), Smithson (1939, 1941), Poldervaart (1955), Eckelman \& Kulp (1956), Murthy \& Siddiquie (1964), Pupin et al. (1969), Zabiyaka \& Makhlayev (1970) e Malcutt \& Heimlich (1972) são alguns dos que escreveram sobre a natureza detrítica dos grãos de zircão arrendondados em rochas sedimentares, metamórficas e ígneas anatéticas.

O significado destes aspectos morfológicos está condicionado ao conceito de que o zircão é um mineral mecanicamente resistente, altamente refratário e geralmente estável sob condições metamórficas, sendo, portanto, capaz de resistir a muitos ciclos geológicos. Pelo menos nos casos em que a idade dos zircões difere largamente da idade de cristalização da rocha, isto deve ser verdade. No entanto, críticas ao uso generalizado das características morfológicas do zircão em interpretaç̃̃es petrogenéticas têm sido feitas desde Winchell (1914), Armstrong (1922) e Mackie (1928). Mais recentemente, Saxena (1966) revisou e criticou o significado dessas características morfológicas. Adiante serão discutidos esses pontos à luz das evidências texturais.

A tipologia do zircão em sua forma moderna considera o desenvolvimento relativo das faces prismáticas e piramidais em cristais euédricos e subeuédricos. Este método foi introduzido por Pupin \& Turco (1972a) e é atualmente aplicado na caracterização de granitóides (Pupin \& Turco 1972b, Pupin 1976, Pupin 1980).

Todas essas observações tipológicas são sempre feitas em concentrados do mineral obtidos por moagem e fracionamento. Todavia, pouco se tem falado sobre a disposição dos grãos na petrotrama.

A associação zircão-biotita A mais notória característica textural do zircão é sua associação com a biotita, especialmente em rochas igneas plutônicas, ácidas e intermediá. rias. Isso geralmente se explica pela cristalização inicial da biotita nessas composições em relação aos demais minerais essenciais. Os acessórios zircão, apatita, monazita, allanita e outros, primeiramente cristalizados, ficam, portanto, inclusos prioritariamente em biotita (Fig. 1-B). Em muitos casos, no entanto, a presença de água e alcalinidade determina a solubilidade do zircão e amplia ou retarda seu campo de cristalização aos estágios finais da consolidação magmática.

Em rochas metaplutônicas, esta relação é mantida, desde que sejam preservadas as biotitas magmáticas ou que a geração de novas biotitas seja apenas por substituição das preexistentes.

Em rochas metassedimentares, os zircões não deveriam ter qualquer associação preferencial com biotitas geradas por metamorfismo, considerando-se a natureza detrítica do acessório e sua distribuição de zircão clástico deveria distribuir-se de forma proporcional entre biotitas metamórficas e demais minerais. Na realidade, biotitas metamórficas também concentram grãos de zircão, mas em menor intensidade que biotitas de cristalização magmática (Fig. 1-A). 
A
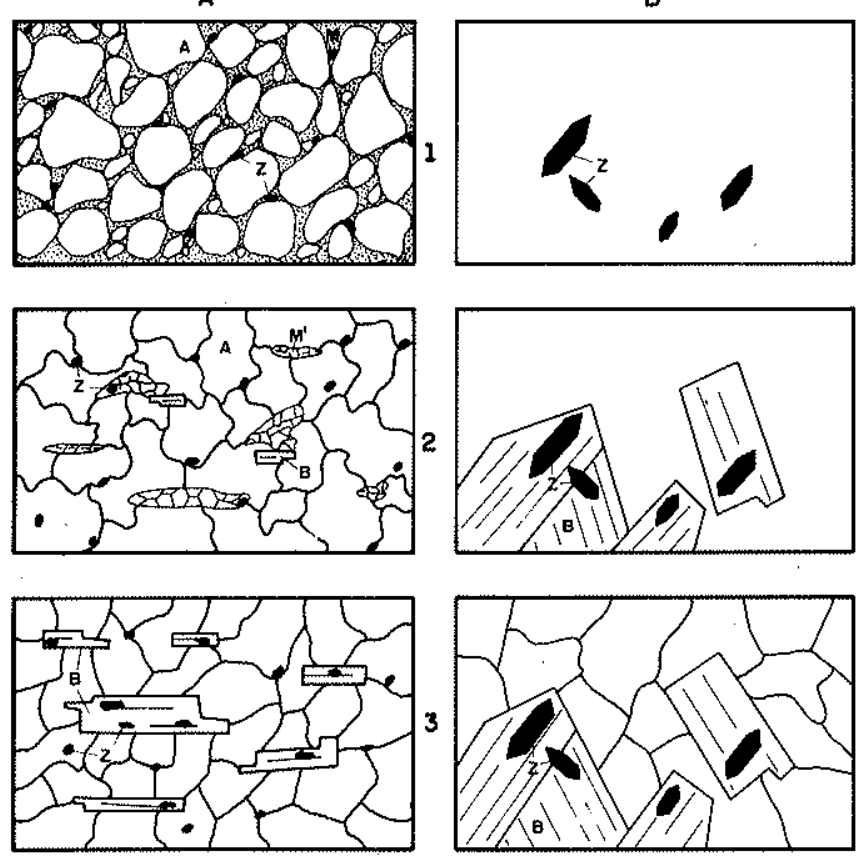

Figura 1 - Evolução textural da associação zircão-biotita em rochas metassedimentares $(A)$ e em rochas igneas plutônicas $(B)$. A.l. Sedimento original com arcabouço $(A)$, matriz (M) e zircões detriticos dispersos (Z). A.2. Inicio do metamorfismo com deformação do arcabouço, recristaçização da matriz (M) e nucleação incipiente de biotita (B). A.3. Rocha totalmente recristalizada com alguma concentração de zircão na biotita. B.1. Cristalização inicial do acessório zircão (Z). B.2. Cristalização de biotita (B) com cristais de zircão inclusos. B.3. Consolidação magmática completada com zircões exclusivamente associados à biotita.

Essas diferentes evoluções texturais justificaram o esforço em se quantificar a associação zircão-biotita em rochas plutônicas, metaplutônicas e metassedimentares, mediante o diagrama biotita modal vs. $100 \times$ zircão (B)/Zircão (T), aqui proposto, e formalmente denominado diagrama $B Z$, em que o zircão (B) é o volume de zircão associado à biotita e zircão (T), o volume total de zircão da rocha.

o DIAGRAMA BZ Métodos Foram selecionadas 82 amostras (19 xistos metassedimentares, dois quartizitos micáceos, 21 paragnaisses, 16 ortognaisses e 24 granitóides) de diferentes localidades e contextos geológicos, e de origem seguramente estabelecida.

Os xistos lançados no diagrama são rochas tipicamente metassedimentares, com minerais aluminosos (granada, cianita, sillimanita, muscovita), e estruturas sedimentares ocasionalmente preservadas (Tab. 1).

Os paragnaisses utilizados são rochas também altamente aluminọsas, bandadas, com paragêneses tipicamente metassedimentares. São kinzingitos (cordierita-granada gnaisses), kondalitos (sillimanita-granada gnaisses) e biotita (-granada) gnaisses do fácies anfibolito (Tab. 2).

Os ortognaisses abrangem composições ácidas, na maioria dos casos granítica; apresentam a mineralogia original pou-
Tabela 1 - Relação de amostras de rochas metassedimentares e suas respectivas procedências.

\begin{tabular}{rclll}
\hline N.o & CóDIGO & CARACTERIZAÇĀO & PROCEDÊNCIA \\
\hline 1 & V.2 & Estaur.-Gran.-Biot.-Musc. & Andrelândia, MG \\
2 & V.5 & Gran.-Cian.-Biot.-Musc. & Andrelândia, MG \\
3 & V.10 & Gran.-Sill.-Biot.-Musc. & Andrelândia, MG \\
4 & 26 & Biot.-QZ.-Musc. & Embu-Guaçu, SP \\
5 & CP 178 & Biot.-QZ.-Musc. & Embu-Guaçu, SP \\
6 & CP131 & Estaur.-Biot.-Musc. & Embu-Guą̧u, SP \\
7 & CP 127 & QZ.-Biot.-Musc. & Embu-Guaçu, SP \\
8 & $19 A$ & Biot.-Musc.-QZ. & Cássia, MG \\
9 & $163 B$ & Gran.-Biot.-QZ. & Cássia, MG \\
10 & XS & Cord.-Gran.-Biot. & Currais Novos, RN \\
11 & CE-5 & Musc.-Biot.-QZ. & Ceará \\
12 & MT-9 & QZ.-Gran.-Biot.-Musc. & Goiás \\
13 & X S S & Sill.-Biot. & São Sebastião, SP \\
14 & MC 490 & Gran.-Biot.-Musc. & Goiás \\
15 & F 24 & Cian.-Biot. & Natividade, GO \\
16 & GNR 14 & Cian.-Gran.-Biot.-Felds. & Nova Resende, MG \\
17 & 140 CK & Biot.-Musc.-Qz. & Alemanha \\
18 & 309 G & Gran.-Biot.-Felds.-QZ. & Juiz de Fora, MG \\
19 & 310 & Gran.-Sill.-Biot.-QZ. & Juiz de Fora, MG \\
20 & 85 A & Biot.-Gran.-Qzito. & Cassia, MG \\
21 & 62 A & Biot.-Cian.-Qzito. & Cássia, MG \\
\hline
\end{tabular}

Tabela 2 - Relação de amostras de paragnaisses e suas respectivas procedências.

\begin{tabular}{ccll}
\hline N.0 & CÓDIGO & CARACTERIZAÇÃO & PROCEDENCIA \\
\hline 22 & 232 & Cord.-Gran. & Itabira, MG \\
23 & 313 A & Biot.-Gran. & Juiz de Fora, MG \\
24 & 2863 & Biot.-Musc. & Itabira, MG \\
25 & 132 C & Gran.-Cord.-Biot. & São José do Rio Pardo, SP \\
26 & P C G K & Congl.-Gnaisse & Quadrilátero Ferrífero, MG \\
27 & $286-1$ & Cord.-Gran.-Biot. & Itabira, MG \\
28 & VB-IA & Cord.-Gran.-Biot. & São José do Rio Pardo, SP \\
29 & $286-2$ & Gran.-Biot. & Itabira, MG \\
30 & $286-4$ & Biot.-Gran. & Itabira, MG \\
31 & $18-F$ & Cord.-Biot.-Gran. & Rio do Prado, MG \\
32 & FV 623 & Biot.-Gran. & Vassouras, RJ \\
33 & 313 B & Biot.-Gran.-Cord. & Juiz de Fora, MG \\
34 & IM-5 & Gran.-Sill.-Biot. & São José do Rio Pardo, SP \\
35 & 1799 B & Biot. & Itabira, MG \\
36 & 1799 C & Biot. & Itabira, MG \\
37 & CK & Cord.-Biot.-Gran. & Alemanha \\
38 & 1799 A & Cord.-Biot.-Gran. & Itabira, MG \\
39 & $18-N$ & Cord.-Gran.-Biot. & Rio do Prado, MG \\
40 & 1796 A & Sill.-Gran.-Biot. & Itabira, MG \\
41 & 334 X & Gran.-Horn.-Biot. & Itabira, MG \\
42 & 1802 & Gran.-Horn.-Biot. & Itabira, MG \\
\hline & & &
\end{tabular}

co alterada por metamorfismo e feições reliquiares ígneas preservadas; estão deformados e recristalizados em diferentes intensidades (Tab. 3).

Os granitóides lançados têm também composição predominantemente granítica e estão pouco afetados por deformação. São corpos intrusivos de diferentes dimensões (Tab. 4). 
Tabela 3 - Relação de amostras de ortognaisses e suas res pectivas procedências.

\begin{tabular}{ccll}
\hline N.o & CÓDIGO & CARACTERIZAÇÃo & PROCEDẼNCIA \\
\hline 43 & SCP 18 & Granito & Embu-Guaçu, SP \\
44 & 7 GF & Granito (Augen) & Niterói, RJ \\
45 & CR-31B & Granito (Blastomilonítico) & Pouso Àlegre, MG \\
46 & FV 502 & Granito & Vassouras, RJ \\
47 & FV 508 & Quartzo monzonito & Vassouras, RJ \\
48 & EX 19 & Quartzo monzonito & Piracaia, SP \\
49 & CR-32 A & Granito (milonítico) & Pouso Alegre, MG \\
50 & 66 & Granito & Embu-Guaçu, SP \\
51 & FV 312 & Quartzo monzonito & Vassouras, RJ \\
52 & CP 38 & Granito & Embu-Guaçu, SP \\
53 & 1 GF & Granito (Augen) & Niterói, RJ \\
54 & 61 GFR & Granito (Augen) & Niterói, RJ \\
55 & EX 13 & Quartzo monzonito & Piracaia, SP \\
56 & CP 80 & Granito & Embu-Guaçu, SP \\
57 & CR 25 & Granito (Blastomilonítico) & Pouso Alegre, MG \\
58 & CR 24 A & Granito & Pouso Alegre, MG \\
\hline
\end{tabular}

Tabela 4 - Relação das amostras de granitóides e suas respectivas procedências.

\begin{tabular}{ccll}
\hline N. & CÓDIGO & CARACTERIZAÇÃO & PROCEDÊNCIA \\
\hline 59 & A7-34A & Granito (aplito) & Amparo, SP \\
60 & GGG & Granito & Guarujá, SP \\
61 & GCK & Granito (2 micas) & Alemanha \\
62 & VG 318 & Graisen grantio & Rondônia \\
63 & GG1 & Granito & Guarujá, SP \\
64 & B 412 & Graisen granito & Rondônia \\
65 & SF 2 & Ảlcali sienito & Anitápolis, SC \\
66 & B 424 & Graisen granito & Rondônia \\
67 & A 95 & Granito & Maciço de Morungaba, SP \\
68 & O-2811 & Graisen granito & Rondônia \\
69 & A 72 & Granito & Maciço de Morungaba, SP \\
70 & A 520 & Granito & Maciço de Morungaba, SP \\
71 & S 126M & Quartzo sienito & Anitápolis, SC \\
72 & PI-2 & Granito & Itatinga, SP \\
73 & P 5C & Quartzo monzonito & Guarulhos, SP \\
74 & A 46 & Quartzo monzonito & Maciço de Morungaba, SP \\
75 & NORCK & Granito & Noruega \\
76 & FV 227 & Granito & Vassouras, RJ \\
77 & 2 CK & Granito & Escócia \\
78 & MA 7 & Granito & Embu-Guaçu, SP \\
79 & 3 CK & Sienito & Alemanha \\
80 & L5 & Quartzo monzonito & Anitápolis, SC \\
81 & P1 189 A & Monzodiorito & Piracaia, SP \\
82 & PI 169 & Quartzo monzonito & Piracaia, SP \\
\hline & & & \\
& & & \\
\hline
\end{tabular}

A quantificação foi realizada em seções delgadas, com a obtenção do percentual modal de biotita (lançado em escala logarítmica para melhor espalhamento dos pontos) e do percentual de zircão associado à biotita 1 zircão (B), (Fig. 2).

$\mathrm{O}$ valor $100 \times$ zircão $(\mathrm{B}) /$ zircão $(\mathrm{T})$ foi obtido varrendo-se toda a lâmina com contagem dos grãos associados à biotita e daqueles associados aos demais minerais (matriz). Por convenção, foram considerados associados à biotita, os grãos que têm com este mineral pelo menos um ponto de contato.

A variação no tamanho dos grãos de zircão é geralmente grande numa mesma amostra. Em vista disso, foram atribuídos pesos diferentes na contagem, conforme o tamanho dos grãos. Os menores grãos foram considerados como a unidade e os demais contados como múltiplos desta unidade. 0 resultado final é uma relação numérica que traduz a distribuição do volume de zircão entre biotita e matriz.

Alguns cuidados devem ser tomados na contagem, pois em geral não se podem efetuar testes 6 pticos pelo reduzido tamanho dos grãos. Deve-se ter familiaridade com a morfologia dos cristais de zircão, pois na maioria dos casos a identificação será feita apenas pela forma e pelo relevo dos grãos.

Monazita, titanita, apatita, epidoto e allanita podem ser confundidos com zircão em grãos pequenos. Deve-se atentar ao fato de esses minerais poderem também gerar auréolas pleocróicas na biotita, muito parecidas com as produzidas por zircão.

É comum também, que, numa primeira vista, se tenha a impressão de que todo ou quase todo o zircão da amostra esteja incluso em biotita. Muitas vezes é uma falsa impressão, determinada apenas pelos halos pleocróicos da biotita, que atraem a atenção do observador. Zircões em minerais descoloridos são menos visiveis e requerem maior acuidade.

Aplicação $\mathrm{O}$ exame do diagrama BZ (Fig. 2) mostra a existência de dois campos perfeitamente individualizados em que se deslocam rochas plutônicas e metaplutônicas de um lado, e rochas metassedimentares de outro. A quantificação da associação zircão-biotita pode, portanto, dar indicação do caráter pré-metamórfico da rocha, desde que o ponto caia nos campos definidos.

Na porção central do diagrama, os resultados são dúbios e não devem servir para caracterizaçðes. Note-se também que a resolução do método é maior com baixos teores de biotita.

A princípio, a aplicação do método deve ter maior validade na caracterização de gnaisses. Sua utilização em mig. matitos pode ser problemática, pois a presença de fases mobilizadas intimamente associadas às rochas pode conduzir os resultados invariavelmente ao campo ígneo. Esta questão será exemplificada e discutida a seguir.

Discussão Das 42 amostras metassedimentares quantificadas, $38(90,5 \%)$ estão situadas abaixo da curva biotita modal $=100 \times$ zircão $(\mathrm{B}) /$ zircão $(\mathrm{T})$, três amostras $(7,1 \%)$ incidem sobre a curva e apenas uma amostra $(2,4 \%)$ está acima.

Considerando-se a geração de biotitas na evolução metamórfica de um sedimento como independente da distribuição de zircão detrítico, deveria ser estatisticamente espera do que o percentual de zircão associado à biotita $[(100 \mathrm{x}$ zircâo (B)/zircão $(\mathrm{T})]$ fosse aproximadamente igual ao percentual de biotita gerada por metamorfismo (biotita modal), determinando a incidência dos pontos aproximada. 


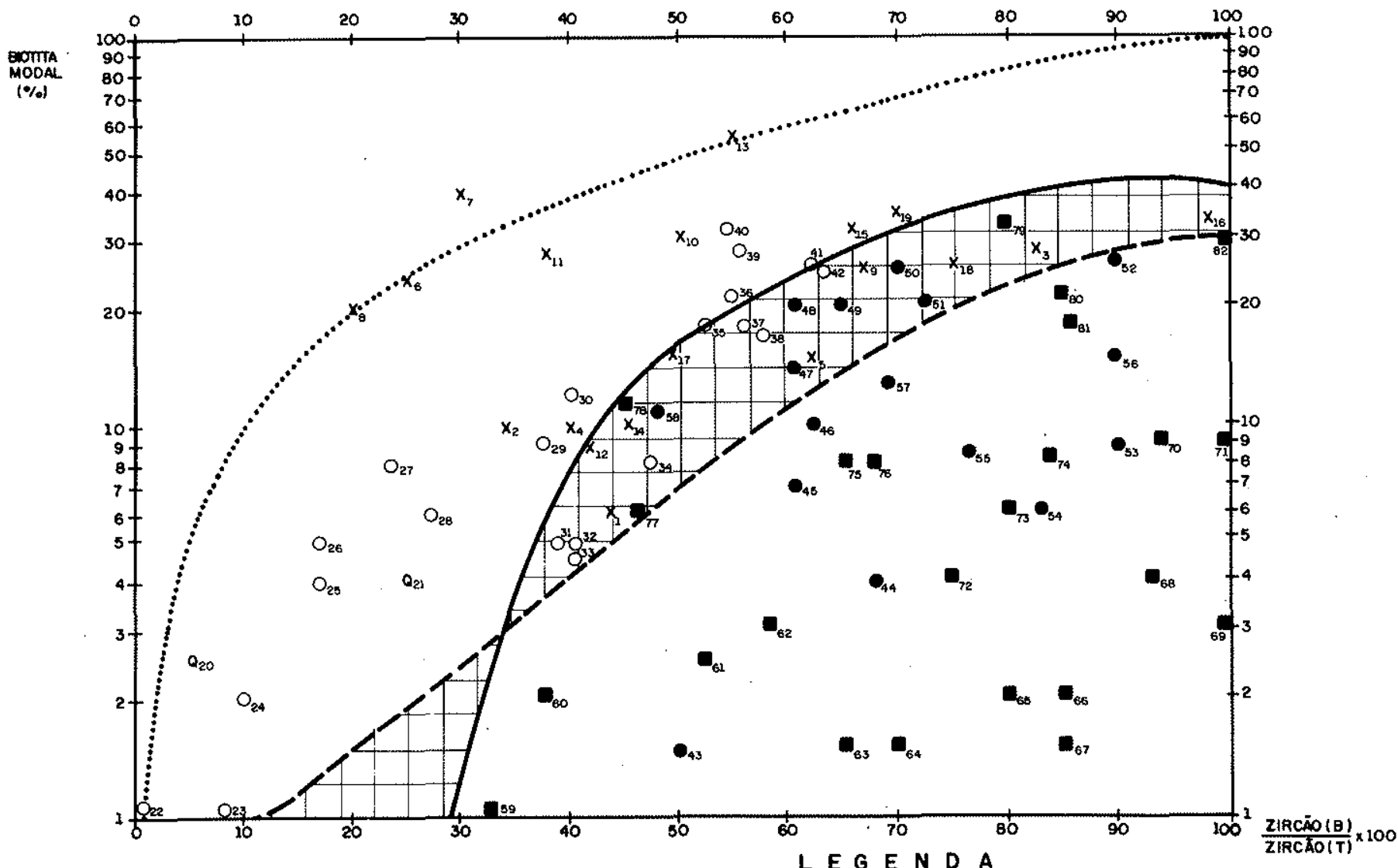

LEGENDA

X XISTO METASSE OIMENTAR

- QUARTZITO MICÁCEO

$\because \ldots \ldots$ CURVA BIOTITA MODAL $=\frac{Z I R C A O(B)}{Z I R C A O(T)} \times 100$

O paragnaisse

- oRTOGNAISSE

- gRANITóIDe
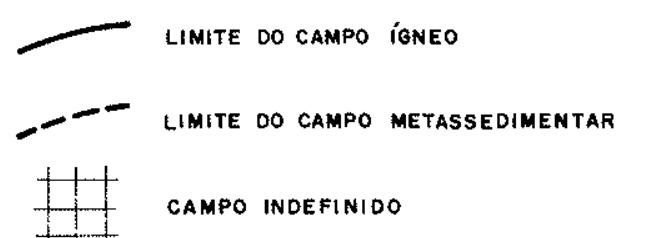

Figura 2 - Rochas metassedimentares, plutônicas e metaplutônicas lançadas no diagrama $B Z$

mente ao longo da curva. Isto decididamente não ocorre. A colocação das amostras metassedimentares predominantemente abaixo da curva significa que biotitas geradas por metamorfísmo também concentram grãos de zircão. Contudo, esta concentração é visivelmente menos pronunciada que em biotitas magmáticas.

Algumas explicações possíveis são:

1. A geração de biotitas metamórficas estaria condicionada à evolução mineralógica da matriz sedimentar e é nesta que se dispersa o zircão detrítico; dai a concentração observada.

2. Boa parte dos grãos de zircão não seria detríticos, mas autigênicos, e estaria intimamente associado a minerais também autigênicos de Fe e Ti (hematita, rutilo). Estes últimos, interagindo com uma matriz potássica, evoluiriam a biotita por incremento de metamorfismo. Saxena (1966) fotografou esta associação e demonstrou que zircões autigênicos podem ser muito semelhantes a zircões detríticos.

3. Formação de zircão por metamorfismo. A associação zircão-biotita como resultado da migração iônica numa mesma direção, mas não necessariamente simultânea de $\mathrm{Fe}$, Ti e $\mathrm{Zr}$ durante a diferenciação metamórfica. Zircões metamórficos têm sido descritos por Taubeneck (1957), Saxena (op. cit.), Zabiyaka \& Makhlayev (1970), Malcutt \& Heimlich (1972) e Ono (1973), mas em muitos casos apenas como sobrecrescimentos em grãos detríticos.

0 exame de dezenas de seções delgadas em rochas metassedimentares diversas permitiu a constatação de que zircões altamente arredondados e escuros, comumente interpretados como resíduos clásticos, na realidade tendem a ter esta forma quando inclusos em quartzo, e sugerem o condicionamento da forma ao hospedeiro (Kretz 1966). Zircões associados à biotita apresentam com muita frequêencia contornos controlados pelo filossilicato (Fig. 3 ).

Essas feições demonstram que zircões arredondados não necessariamente significam grãos clásticos desgastados por transporte e que pelo menos alguns cristais são posteriores à geração de biotitas metamórficas (explicação 3).

Os paragnaisses se dispõem no diagrama segundo um trend linear a 45 graus com os eixos do diagrama (Fig. 4). Isso significa que a associação zircão-biotita se intensifica exponencialmente com o incremento da quantidade de bio. tita na rocha.

Os xistos metassedimentares com mais de $20 \%$ de biotita apresentam uma grande variação na distribuição đo zircão. 


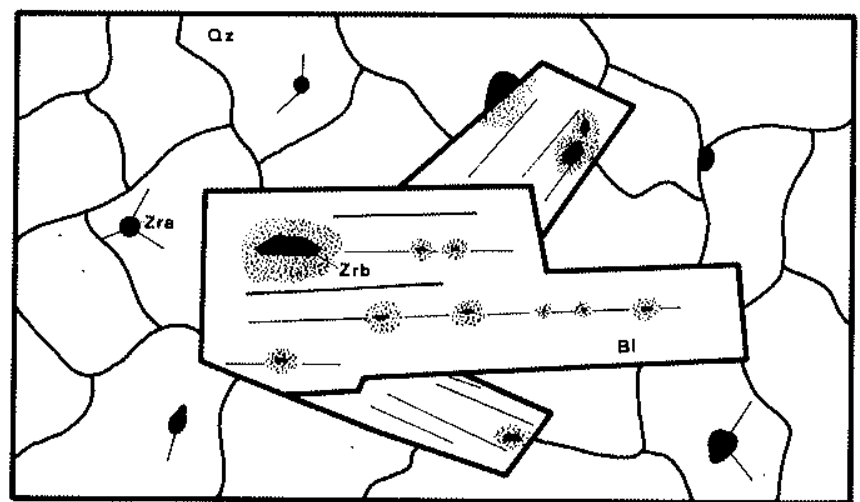

Figura 3 - Aspecto textural em rochas metassedimentares, zircões arrendondados (Zra) inclusos em quartzo $(Q z)$ com fraturas radiais no hospedeiro, e zircões (Zrb) associados à biotita (Bi) com contornos controlados pelos planos (001) do filossilicato. O pontilhado representa halo pleocróico

As amostras 3,16 e 18 são as que têm biotitas mais enrique- cidas em zircão. A amostra 3 (xisto de zona da sillimanita) seguramente apresenta uma anatexia incipiente, já conhecida das descrições do Grupo Andrelândia (ver Trouw et al. 1984). A amostra 16 é um xisto altamente K-feldspático com muitos cristais em geminação Carlsbad, o mesmo ocorrendo com a amostra 18. Em todas as demais amostras de xistos, a participação de feldspatos é subordinada. Esses fatos podem indicar uma participação de mobilizados também na constituição dos xistos 16 e 18. Objetivamente, pode-se dizer que, pelo menos no caso da amostra 3 , a existência de uma fase mobilizada favoreceu a associação zircão-biotita (comparar com as amostras 1 e 2 da mesma localidade, mas desprovidas de mobilizados).

Ortognaisses e granitóides espalham-se aproximadamente pelo mesmo campo. No entanto, existe uma tendência a que ortognaisses tenham biotitas menos enriquecidas em grãos de zircão do que granitóides não deformados. Isto é coerente, pois uma das manifestaçoes de deformação em biotita são os deslizamentos ao longo dos planos (001), com liberação mecânica dos grãos de zircão, que então se associam à matriz.

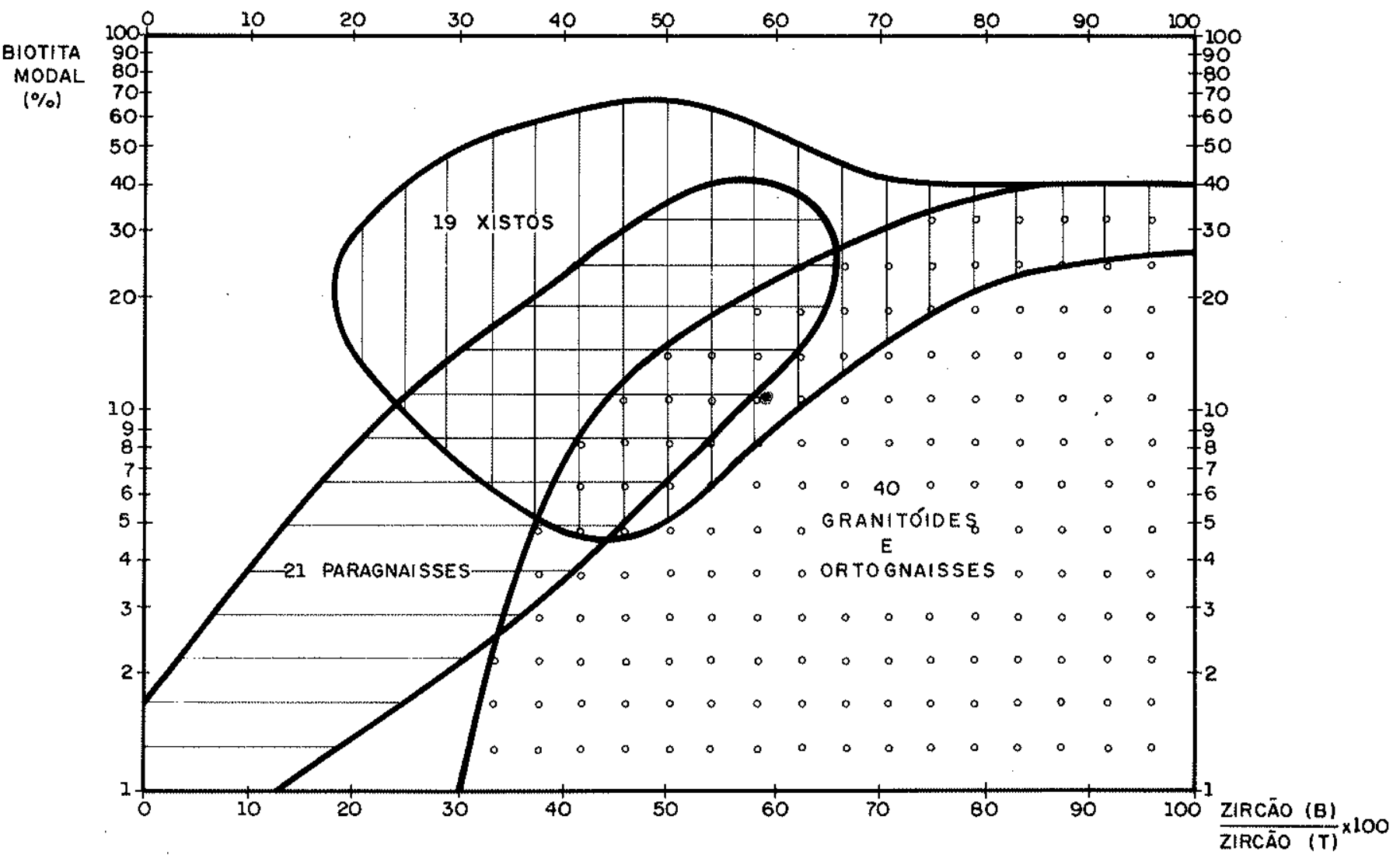

Figura 4 - Disposif̧ão dos campos no diagrama $B Z$

CONCLUSÕES As conclusões principais do trabalho são sumarizadas como segue:

1. A associação textural zircão-biotita pode ser quantificada o diagrama $\mathrm{BZ}$.

2. Rochas plutônicas, metaplutônicas e rochas metasse. dimentares dispõem-se em campos perfeitamente diferenciados no diagrama.

3. O diagrama BZ constitui-se um critério petrográfico de caracterização pré-metamórfica.
4. Zircões arredondados em metassedimentos nem sempre devem ser interpretados como zircões detríticos.

5. Pelo menos em alguns casos, a formação de zircão é posterior à geração de biotitas metamórficas, o que exclui uma origem detrítica e vincula a formação de zircão ao processo metamórfico.

Agradecimentos $\mathrm{O}$ autor agradece ao Conselho Nacional de Desenvolvimento Científico e Tecnológico (CNPq) pela concessão da bolsa de estudos. Também aos profes. 
sores e pós-graduandos do Instituto de Geociências da USP, pelas facilidades de manipulação de suas coleções particulares. Um especial agradecimentos aos amigos. Dr. José Vicen- te Valarelli, Dr. Rômulo Machado e geólogo Valdecir de Assis Janasi, pelo estímulo, presteza e validade de suas críticas e observações.

\section{REFERÊNCIAS BIBLIOGRÁFICAS}

ARMSTRONG, P. - 1922 - Zircon as criterion of igneous or sedimentary metamorphics. Am.J.Sci, 5(4): 391-395.

ECKELMAN, F.D. \& KULP, J.L. - 1956 - The sedimentary origin and stratigraphic equivalence of the so-called Cranberry and Henderson Granites in western North Carolina. Am. J. Sci., 254: 228-315.

GROVES, A.W. - 1930 - The heavy mineral suite and the correlation of the granites of northern Brittany, the Channel Islands, and the Cotentin. Geol. Mag., 67:21 8-240.

KRETZ, R. - 1966 - Interpretation of the shape of mineral grains in metamorphic rocks. J. Petrol., 7(1): 68-94.

LARSEN, L. H. \& POLDERVAART, A. - 1957 - Measurement and distribution of zircons in some granitic rocks of magmatic origin. Mineral Mag., 31:544-564.

MACKIE, W. - 1928 - The heavier accessory minerals in the granites of Scotland. Trans. Edinburgh Geol. Soc., 12:22-40.

MALCUTT, R.J. \& HEIMLICH, R.A. - 1972 - Zircons from Precambrian gneiss, southern Bighorn Mountains, Wyoming. Amer. Miner., 57:1190-1209.

MURTHY, M.V.N. \& SIDDIQUIE, H.N. - 1964 - Studies on zircons from some garnetiferrous sillimanite gneisses (Khondalites) from Orissa and Andhra Pradesh, India. J. Geol., 72:123-127.

ONO, A. - 1973 - Zircons from the Ryoke metamorphic in the Takato-Shiojiri area, central Japan. J. Geol. Soc. Japan, 80:187-191.

POLDERVAART, A. - 1950 - Statistical studies of zircon as a criterion in granitization. Nature, $165: 574-575$.

POLDERVAART, A. - 1955 - Zircon in rocks. I. Sedimentary rocks. Am. J. Sci., 253:433-461.

POLDERVAART, A. - 1956 - Zircons in rocks. II. Igneous rocks. Am. J. Sci., 254:521-554.

POLDERVAART, A. \& Von BACKSTROM, J.W. - 1950 - A study of an area at Kakamas (Cape Province). Trans. Geol. Soc. S. Africa, 52:433-495.

PUPIN, J.P. - 1976 - Signification des caractères du zircon commun des roches en pétrologie. Base de la méthode typologique. Applications. (These Doct. Etat., Univ. Nice, France) 394 p.
PUPIN, J.P. - $1980-$ Zircon and granite petrology. Contrib. Mineral. Petrol, $73: 207-220$.

PUPIN, J.P. \& TURCO, G. - 1972a - Une typologie originale du zircon acessoire. Bull. Soc. Fr. Mineral. Cristallogr., 95:348-359.

PUPIN, J.P. \& TURCO, G. - 1972b - Application des données morphologiques du zircon acessoirie en pétrologie endogène. C.R. Acad. Sci. Paris, 275(D):799-802.

PUPIN, J.P.; BOUCAROUT, M.; TURCO, G.; GUEIRARD, S. 1969 - Les zircons des granites et migmatites du massif de l'Argentera-Mercantour et leur signification pétrogènétique. Bull. Soc. Fr. Mineral. Cristalogr. 922(5):472-483.

SAXENA, S.K. - 1966 - Evolution of zircons in sedimentary and metamorphic rocks. Sedimentology, 6(1):1-33.

SMITHSON, F. - 1939 - Statistical methods in sedimentary petrology. Geol. Mag., 76:297-309, 348-360, 417-427.

SMITHSON, F. - 1941 - The alteration of the detrital mineral in the mesozoic rocks of Yorkshire, a petrological and paleogeographical study. Geol. Soc. London, Quart. J., 98:27-59.

TAUBENECK, W.H. - 1957 - Zircons in the metamorphic aureola of the Bald Mountain batholith, Elkhorn Mountains, northeastern Oregon. Bull. Geol. Soc. Amer., 68:1803 (Abstract).

TROUW, R.A.J.; RIBEIRO, A.; PACIULLO, F.V.P; HEILBRON, M.L. - 1984 - Os Grupos São João del Rei, Carrancas e Anđrelândia, interpretados como a continuação dos Grupos Araxá e Canastra. In: CONGR. BRAS. GEOL., 33, Rio de Janeiro, 1984. Anais.. Rio de Janeiro, SBG. v. 7, p. $3227-3240$.

WINCHELL, A.N. - 1914 - Mining districts of the Dillon quadrangle, Montana, and adjacent areas. Geol. Surv. Bull., 574:11-191.

ZABIYAKA, I.D. \& MAKHALAYEV, L.V. -1970 - Evolution of accessory zircon during progressive ultrametamorphism as illustred by the Precambrian granitoids of Taymir. Dokl. Acad. Sci. USRR. Earth Sci. Sect., 191:144-146.

MANUSCRTTO

Recebido em 04 de marco de 1986 Revisão aceita em 09 de maio de 1986

". . . o homem, por ser dotado de uma inteligência livre, tornou-se um falsificador da natureza, um agente de desordem".

Emberger - Atas Soc. Helv. Sci. Nat., 1960: 31-43. 